\title{
Microvascular Capillary Plexus Findings of Commotio Retinae on Optical Coherence Tomography Angiography
}

\author{
Ahmad M. Mansour ${ }^{a, b} \quad$ Carol L. Shields ${ }^{c}$ \\ aDepartment of Ophthalmology, American University of Beirut, Beirut, Lebanon; \\ ${ }^{b}$ Department of Ophthalmology, Rafic Hariri University Hospital, Beirut, Lebanon; \\ 'Ocular Oncology Service, Wills Eye Hospital, Thomas Jefferson University, \\ Philadelphia, PA, USA
}

\section{Keywords}

Commotio retinae - Berlin's edema - Optical coherence tomography angiography · Spectral-domain optical coherence tomography $\cdot$ Traumatic maculopathy

\section{Abstract}

Optical coherence tomography $(\mathrm{OCT})$ and histopathology features of commotio retinae (CR) have been established, but alterations of the microvascular macular capillary plexus on OCT angiography (OCTA) has not been previously studied. We present a 46 -year-old man who sustained a tennis ball injury to the right eye with visual acuity reduction to 20/30 and grey-white deep macular discoloration, suggestive of CR. Spectral-domain OCT (SD-OCT) showed increased reflectivity and thickness of the ellipsoid zone (junction of photoreceptor inner and outer segments). OCTA revealed no apparent microvascular alterations (right versus left eye) in the foveal avascular zone superficial $\left(0.42 \mathrm{vs} .0 .43 \mathrm{~mm}^{2}\right)$ and deep $\left(0.45 \mathrm{vs} .0 .44 \mathrm{~mm}^{2}\right)$, superficial foveal capillary density (34.1 vs. $32.6 \%$ ), and superficial parafoveal capillary density (55.2 vs. $52.2 \%$ ). Deep macular capillary plexus and choriocapillaris were qualitatively comparable between the two eyes. At 2 months' follow-up, SD-OCT had normalized. CR is characterized by disruption of the ellipsoid zone without detectable alteration of the capillary plexuses. 


\section{Introduction}

Commotio retinae (CR) is an outer retinal disturbance that follows blunt trauma to the eye and can lead to temporary or permanent loss of vision [1-7]. This condition is not uncommon in clinical practice and especially related to sports injuries or traffic accidents. Clinically, CR is characterized by transient gray-white retinal discoloration accompanied by fairly abrupt reduction of visual acuity following closed-eye blunt globe trauma $[2,3,8]$. The fundus findings can be limited to the posterior pole (Berlin's edema [9], traumatic maculopathy) or peripheral areas of the retina (retinal contusion). Histopathologically, CR is characterized by disruption of the photoreceptor outer segments (OS), typically without injury to other retinal layers [4]. Using spectral-domain optical coherence tomography (SD-OCT) the condition has been recognized as a disturbance in the ellipsoid layer with hyperreflectivity [1-3, 5]. Herein, we describe novel OCT angiography (OCTA) findings of both the superficial and deep capillary plexus in CR.

\section{Case Report}

A 46-year-old male army colonel sustained blunt injury to the right eye following direct contact with a tennis ball to the closed eyelid. Three hours later, visual acuity was 20/30 in the right eye and 20/20 in the left eye with central corneal abrasion, mild anterior chamber cells, flare, and a localized gray-white oval discoloration in the macula of the right eye. Topical corticosteroid ointment and systemic corticosteroid ( $50 \mathrm{mg}$ prednisone daily for 5 days) were started. At $20 \mathrm{~h}$ following trauma, high-definition SD-OCT and OCTA were obtained through clear cornea.

\section{Results}

By SD-OCT (Optovue Inc., Fremont, CA, USA) central macular thickness was $262 \mu \mathrm{m}$ in the right eye and $271 \mu \mathrm{m}$ in the left eye, and there was broad increased reflectivity of the ellipsoid layer (junction of photoreceptor inner segment [IS] and OS) in the region affected by CR (Fig. 1). The inner retinal architecture was preserved. OCTA using AngioVue ${ }^{\circledR}$ (Optovue Inc.) revealed no qualitative microvascular alterations in the capillary plexus and choriocapillaris (Fig. 2). Quantitative measurements (right versus left eye) included the foveal avascular zone superficial ( 0.42 vs. $\left.0.43 \mathrm{~mm}^{2}\right)$ and deep ( 0.45 vs. $\left.0.44 \mathrm{~mm}^{2}\right)$, foveal capillary density superficial (34.1 vs. $32.6 \%$ ), and parafoveal capillary density superficial (55.2 vs. $52.2 \%$ ) (Fig. 2, 3). One week after trauma, visual acuity had returned to $20 / 20$ in each eye with minimal residual grayish hue without a foveal reflex in the right eye. Repeat SD-OCT 2 months after trauma revealed resolution of the reflectivity at the ellipsoid layer in the right eye and normal central macular thickness (246 $\mu \mathrm{m}$ right vs. $251 \mu \mathrm{m}$ left) in each eye (OCT 3D-2000 Topcon FA plus, Topcon, Tokyo, Japan).

\section{Discussion}

In the current study, no evident alterations of the retinal or superficial choroidal vessels were noted in CR. Hence, there was absence of any occlusion of the retinal capillaries in the 
area of grayish discoloration of the retina; in contradistinction, indocyanine green angiography showed a defect in choroidal inflow, probably corresponding to spasm of the choroidal artery, at the CR lesion site in 9 out of 21 patients [8]. Hashimoto et al. [10] documented a decrease in the choroidal blood flow using laser speckle flowgraphy in one case of CR. It could be argued that OCTA was done $24 \mathrm{~h}$ after trauma and missed the acute spasm of the superficial choroidal circulation, or that the trauma was not very severe to induce a vasogenic response. Swept-source OCTA and indocyanine angiography were not done in the current case to analyze the changes in the deeper choroidal circulation.

There is absence of intraretinal edema in most cases of mild to moderate CR as there is no thickening of the retina, hence Berlin's edema is a misnomer. In 1873, Berlin [9] attributed the grayish discoloration of the fundus to the extracellular retinal edema. The junction between outer photoreceptor and retinal pigment epithelium is a sensitive junction and is most susceptible to disruption from minor or severe blunt trauma. Using SD-OCT, Souza-Santos et al. [1] noted that mild CR showed transient hyperreflectivity of the outer retina implicating good prognosis, whereas disruption of the IS/OS junction in more severe CR, especially with hyperreflectivity of the overlying retina, was associated with poor vision prognosis. Similarly, Ahn et al. [5] divided CR severity into four grades useful also in predicting visual outcomes: increase in IS-OS junction reflectivity with the disappearance of the thin hyporeflective optical space (grade 1), cone OS tips defect only (grade 2), cone OS tips and IS-OS junction defects (grade 3), and cone OS tips, IS-OS junction, and external limiting membrane defects (grade 4). Itakura and Kishi [2] and Pham et al. [3] documented restoration of photoreceptor OS in CR by SD-OCT along with visual recovery after blunt trauma as in our case. More severe ocular injuries resulted in retinal pigment epithelium disruption in the macular region and irreversible loss of vision [1]. In general there is an average visual gain of $0.18 \log M A R$ after macular CR within 3-4 weeks after trauma [6].

\section{Conclusion}

We did not detect any retinal vascular changes (superficial plexus, deep plexus, choriocapillaris) in CR by OCTA localizing the damage to the OS layer well described by histopathology (disruption of the IS/OS junction) and SD-OCT (increased reflectivity of the photoreceptor OS). Further analysis of the choroidal circulation in CR by swept-source OCT is needed.

\section{Statement of Ethics}

The authors have no ethical conflicts to disclose.

\section{Disclosure Statement}

The authors have no conflicts of interest to declare. 
Mansour and Shields: Microvascular Capillary Plexus Findings of Commotio Retinae on Optical Coherence Tomography Angiography

\section{Author Contributions}

A.M. Mansour: original idea, acquisition, collection of data, writing of the manuscript, and final approval of the manuscript to be published. C.K. Shields: original idea, study design, interpretation of data, writing of manuscript revision, and final approval of the manuscript to be published. Both authors read and approved the final manuscript.

\section{References}

1 Souza-Santos F, Lavinsky D, Moraes NS, Castro AR, Cardillo JA, Farah ME. Spectral-domain optical coherence tomography in patients with commotio retinae. Retina. 2012 Apr;32(4):711-8.

2 Itakura H, Kishi S. Restored photoreceptor outer segment in commotio retinae. Ophthalmic Surg Lasers Imaging. 2011 Mar 3;42 Online:e29-31.

3 Pham TQ, Chua B, Gorbatov M, Mitchell P. Optical coherence tomography findings of acute traumatic maculopathy following motor vehicle accident. Am J Ophthalmol. 2007 Feb;143(2):348-50.

4 Mansour AM, Green WR, Hogge C. Histopathology of commotio retinae. Retina. 1992;12(1):24-8.

5 Ahn SJ, Woo SJ, Kim KE, Jo DH, Ahn J, Park KH. Optical coherence tomography morphologic grading of macular commotio retinae and its association with anatomic and visual outcomes. Am J Ophthalmol. 2013 Nov;156(5):994-1001.e1.

6 Blanch RJ, Good PA, Shah P, Bishop JR, Logan A, Scott RA. Visual outcomes after blunt ocular trauma. Ophthalmology. 2013 Aug;120(8):1588-91.

7 Blanch RJ, Ahmed Z, Berry M, Scott RA, Logan A. Animal models of retinal injury. Invest Ophthalmol Vis Sci. 2012 May;53(6):2913-20.

8 Kohno T, Miki T, Hayashi K. Choroidopathy after blunt trauma to the eye: a fluorescein and indocyanine green angiographic study. Am J Ophthalmol. 1998 Aug;126(2):248-60.

9 Berlin R. Zur sogennanten Commotio Retinae. Klin Monatsbl Augenheilkd. 1873;11:42-78.

10 Hashimoto R, Hirota A, Maeno T. Choroidal blood flow impairment demonstrated using laser speckle flowgraphy in a case of commotio retinae. Am J Ophthalmol Case Rep. 2016 Aug;4:30-4. 


\section{Case Reports in Ophthalmology}

\begin{tabular}{l|l}
\hline Case Rep Ophthalmol 2018;9:473-478 \\
\hline DOI: 10.1159/000494916 & $\begin{array}{l}\text { @ 2018 The Author(s). Published by S. Karger AG, Basel } \\
\text { www.karger.com/cop }\end{array}$ \\
\hline
\end{tabular}

Mansour and Shields: Microvascular Capillary Plexus Findings of Commotio Retinae on Optical Coherence Tomography Angiography
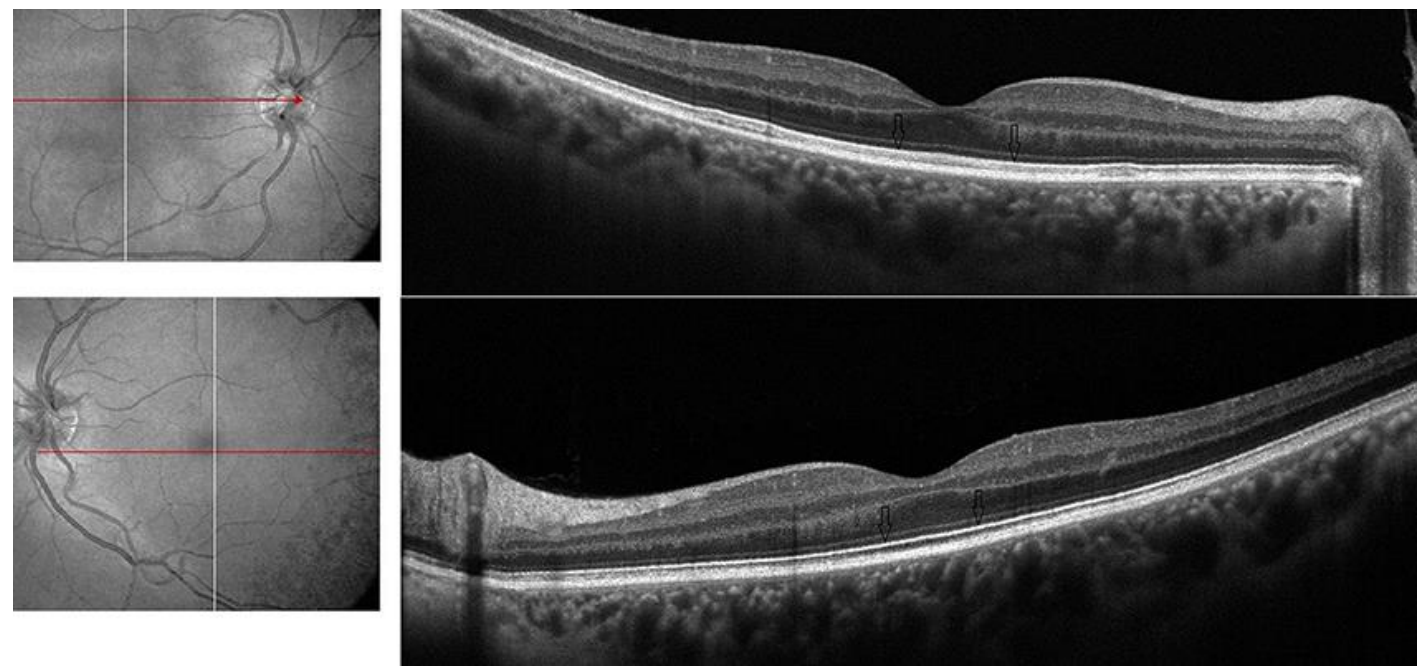

Fig. 1. High-definition SD-OCT of the right and left macula showing comparable retinal and choroidal thickness through the horizontal scans from the disc to the fovea. There is increased reflectivity of the line at the junction between the photoreceptor IS and OS (ellipsoid layer, arrows) in the area of the opacified right macula.
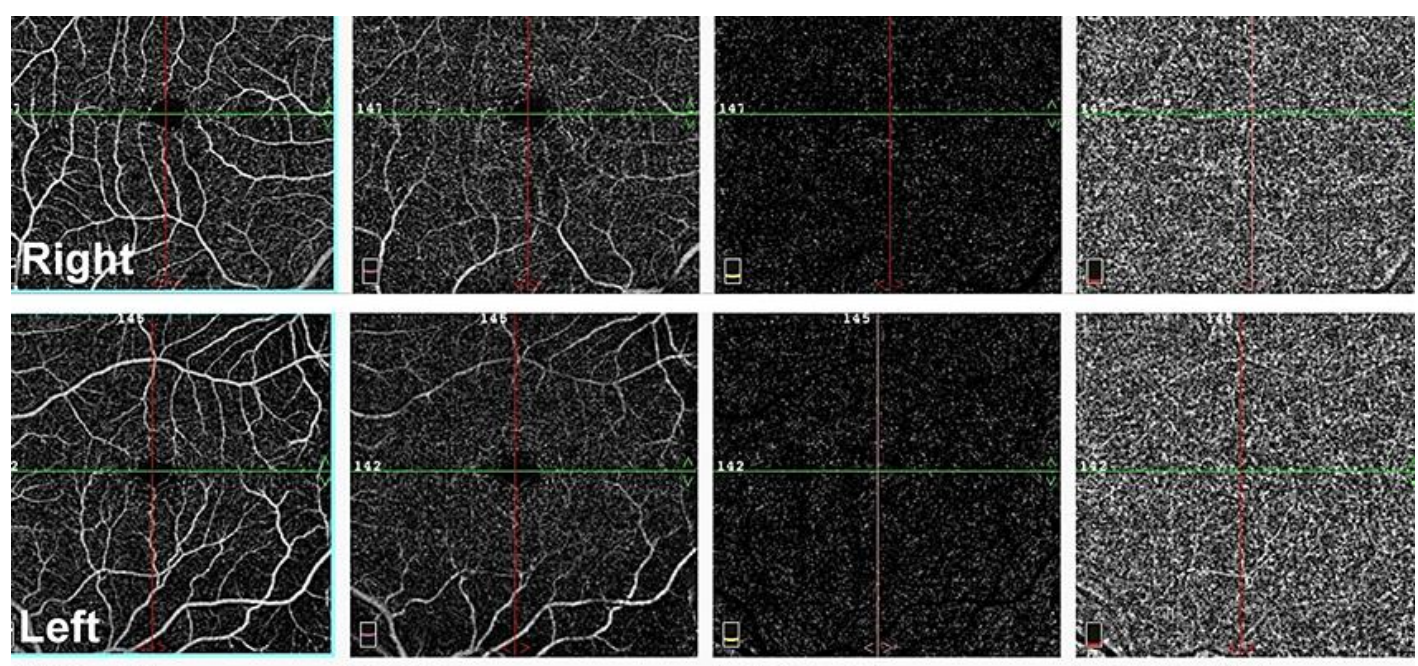

io/ OCT - Superficial

Angio/ OCT - Doop

Angio/OCT - Ovier Retina

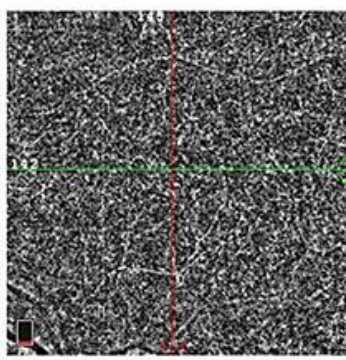

Angio / OCT - Choroid Capilan

Fig. 2. OCTA of the right and left macula showing all four scans (the superficial capillary plexus, deep capillary plexus, outer retina, and choriocapillaris) comparable between the traumatized right eye (top) and the normal left eye (bottom). 


\section{Case Reports in Ophthalmology}

\begin{tabular}{l|l}
\hline Case Rep Ophthalmol 2018;9:473-478 \\
\hline DOI: 10.1159/000494916 & $\begin{array}{l}\text { @ 2018 The Author(s). Published by S. Karger AG, Basel } \\
\text { www.karger.com/cop }\end{array}$ \\
\hline
\end{tabular}

Mansour and Shields: Microvascular Capillary Plexus Findings of Commotio Retinae on Optical Coherence Tomography Angiography
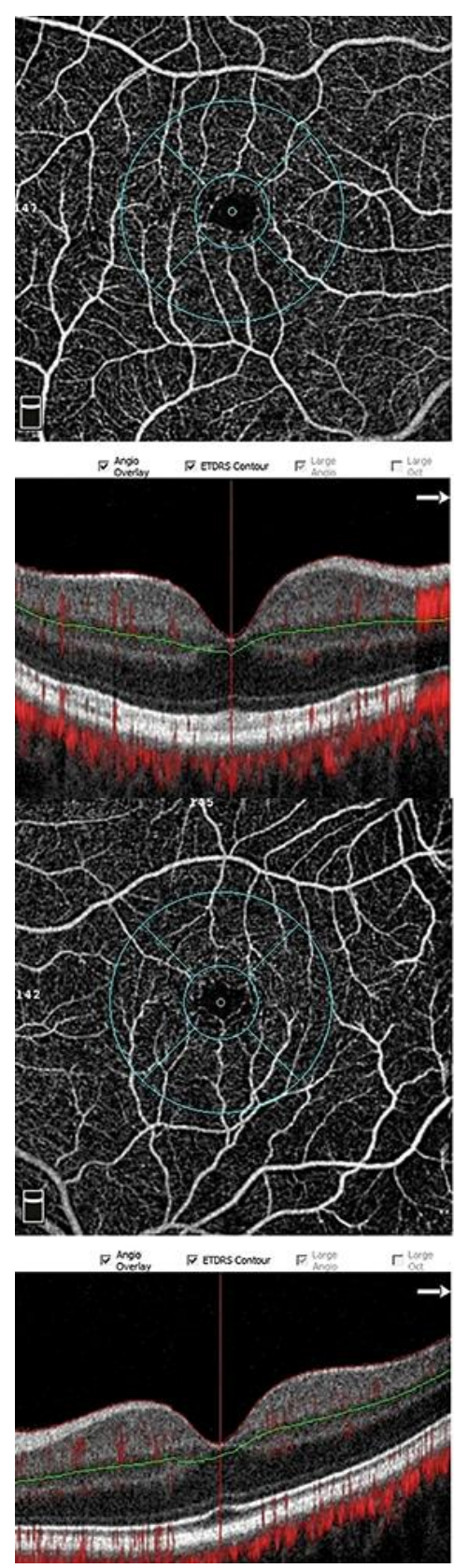
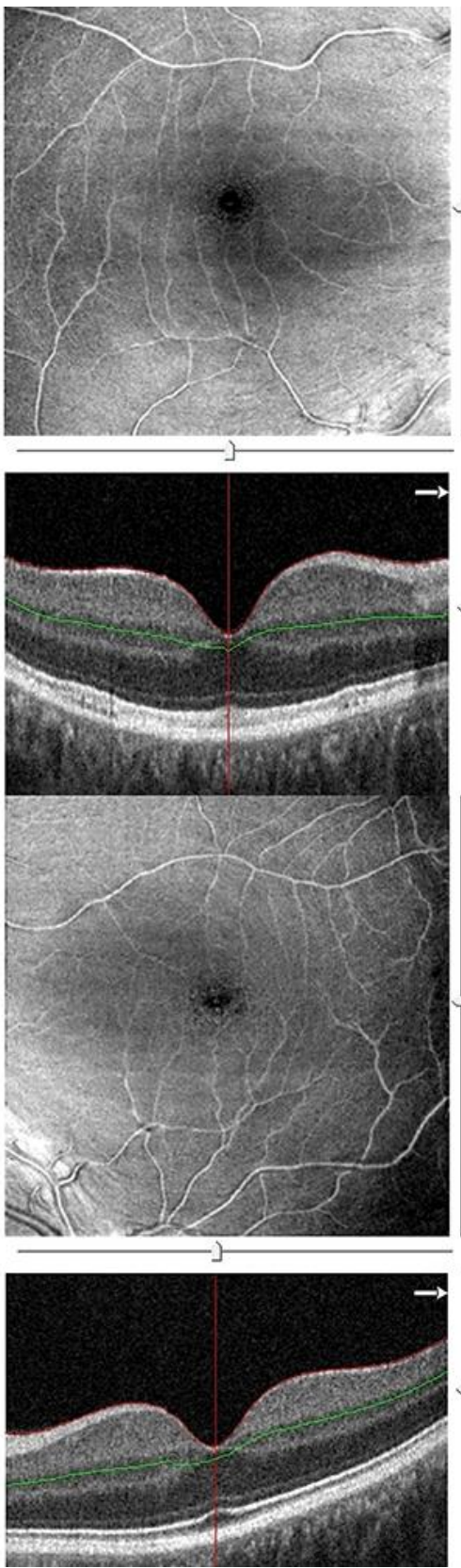
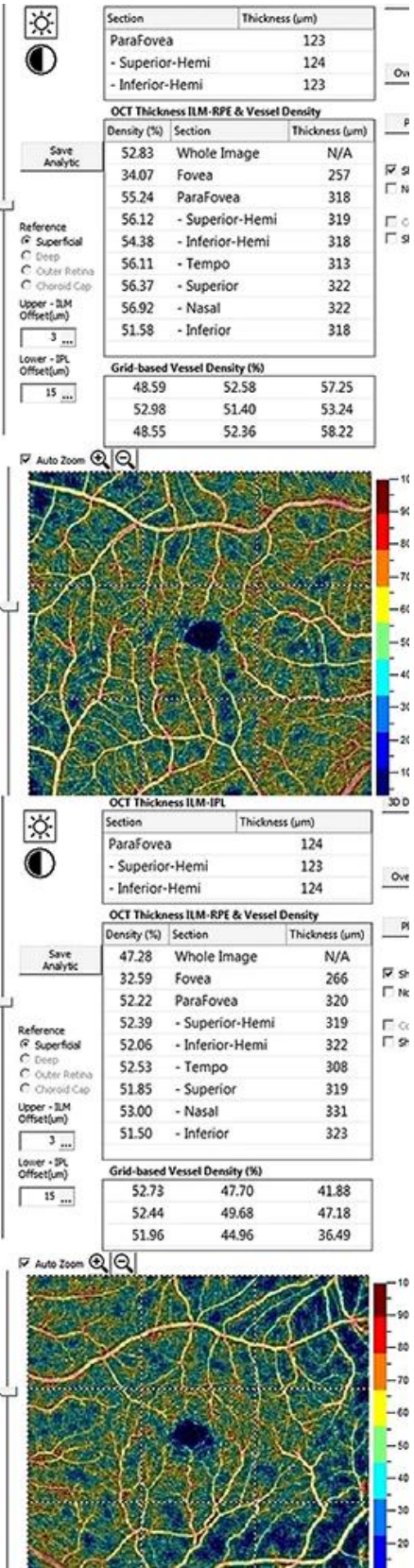

Fig. 3. Vessel density was comparable between the right and left fovea and perifovea by OCTA measurements. 